\title{
The controlling and monitoring system in oyster mushroom cultivation using fuzzy logic through web technology integrated with Internet of Things
}

\author{
Muhammad Priyono Tri Sulistyanto ${ }^{1, *}$, Wahyudi Harianto $^{1}$, Danang Adi Nugroho ${ }^{1}$, Rio Eka Retandi ${ }^{1}$, Aji Kusuma Akbar ${ }^{1}$, \\ and Prantasi Harmi Tjahjanti ${ }^{2}$ \\ ${ }^{1}$ Universitas Kanjuruhan Malang, Informatics Study Program, Jl. S. Supriadi No.48 Malang East Java, Indonesia \\ ${ }^{2}$ Universitas Muhammadiyah Sidoarjo, Program Studi Teknik Mesin, Fakultas Teknik Mesin, Jalan Majapahit 666 B, Sidoarjo, Indonesia
}

\begin{abstract}
Application of intelligent system technology can help human work, especially in this case to support oyster mushroom (Pleurotus ostreatus) cultivation. In mushroom treatment, it needs to water this mushroom periodically using clean water to keep the humidity and temperature suitable. Oyster mushroom can grow and develop with temperature in range 15 to 30 degree Celcius and relative humidity in range 80 to 90 percent's. Farmer's still water mushrooms manually depending on their feeling. The proposed system utilizes Fuzzy Logic to control temperature and humidity as parameter inputs by spraying waters in some duration as output in fuzzy logic. This system as well can monitor those parameters and send them to server computer periodically and do spraying from smartphone that is connected to this server by Internet of Things technology.
\end{abstract}

\section{Introduction}

The era of Industry 4.0 makes the information technology revolution to be part of the driving force of the economy. The concept of cyber physical systems (CPS) makes connections between cyber worlds with real world. The relationship between these two areas is done through the integration between $3 \mathrm{C}$ (communicate, compute and control) that utilize computer systems and communication core extensively [1]. Interchangeable communication between several computer systems is done by machine to machine (M2M) way, one of which is through IoT (Internet of Things) which uses Internet intermediaries. Internet of Thing (IoT) can be interpreted as the internetworking of embedded systems with electronics, software, sensors, actuators, and network connectivity that enable these objects to communicate each other by collecting and exchanging data though the internet [2]. Mostly, the implementations of IoT use embedded systems as controllers, data recorders and data transmitters from sensors and actuators to server computers [3][4].

In this paper, authors describe the utilization of IoT in controlling the temperature and humidity of oyster mushrooms by being integrated with the fuzzy logic controller. Oyster mushroom is one type of wood mushroom because it grows in the weathered wood media. The shape of its hood is slightly rounded, oval and curved like oyster shells. Oyster mushroom has high nutritional content that makes many peoples, especially in Indonesia, interest to cultivate them. To get maximum result on mushroom growth, farmers must be careful in maintaining temperature and humidity, because oyster mushroom can grow well with temperature $15-30^{\circ} \mathrm{C}$ and humidity $80 \%-90 \%[5]$.

\section{Design of embedded system}

The process of an automatic controlling and monitoring of oyster mushroom cultivation begins with detection of sensors as inputs. The inputs of time, temperature and humidity further are processed by Arduino Uno [6] as microcontroller using fuzzy logic calculation. The output of Arduino Uno produces time delay of spray system that connected to relay.

\subsection{Block diagram of system}

Parts of systems are shown in Fig. 1 and Fig. 2 that described as follows:

- DHT 11 [7] which serves as Temperature and humidity sensor whose data will be processed as inputs.

- RTC [8] is time input to know about time condition.

- The Arduino is the brain of a system [9]

- The LCD with I2C interface is used for showing output.

- Relay and spray system, which is used for spraying systems that use special dynamo sprinklers

- Ethernet shield is electronic module for connecting to internet

\footnotetext{
${ }^{*}$ Corresponding author: m.priyono.ts@unikama.ac.id
} 
- Web server is the computer that collect data that sent by Arduino

- $\quad$ PC or Gadgets are computer systems for accessing data and manual controlling of

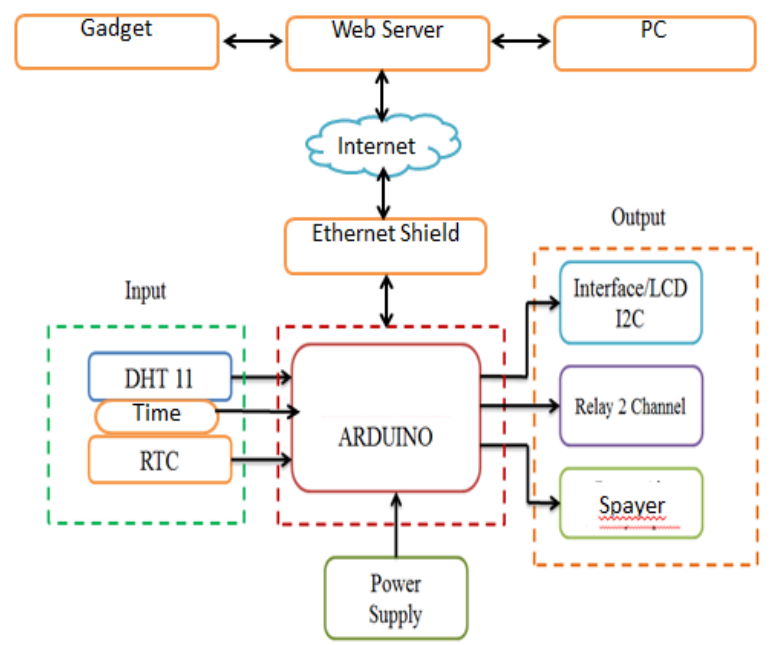

Fig. 1. Overall schematic diagram of monitoring and controlling systems.

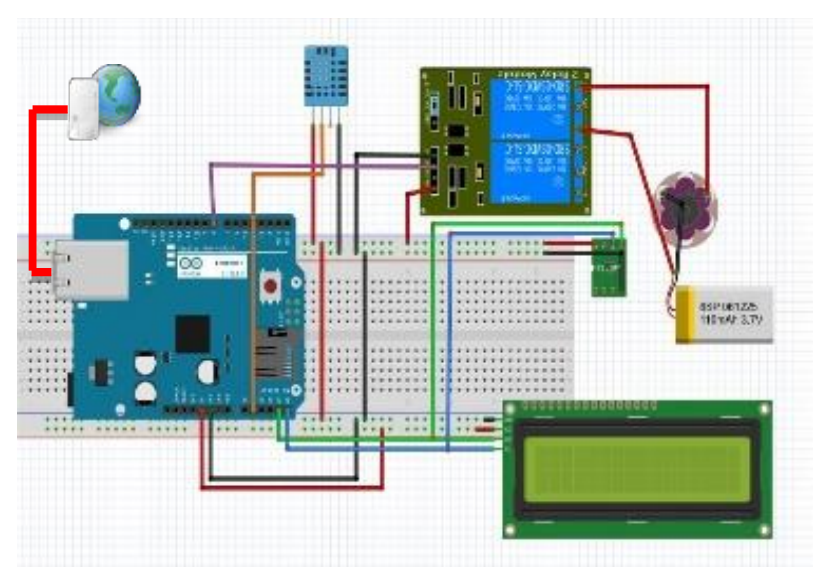

Fig. 2. Visual schematic of systems (drawn using fritzing [10]).

\section{Design of fuzzy logic controller}

Fuzzy logic is an enhancement of Boolean logic that introduces the concept of partial truth. Classical logic (Crips logic) states that everything can be manifested in the binary domain (black or white, 0 or 1 , yes and no), so there is no value between highest value and lowest value [11][12]. Fuzzy logic replaces highest value of Boolean logic with the level of truth, it means there is a value between black and white (grey)[13]. The reason for the use of fuzzy logic are (1) easy to understand because of its simple mathematical concepts, (2) very flexible, (3) tolerance of improper data (4) capable to modelling complex non-linear functions (5) be able to apply expert experience directly without training process, (6) be able to cooperate with conventional control techniques, and (7) based on natural language.

To write program in Arduino that uses ATmega microcontroller series, it uses fuzzy logic library from
eFLL (embedded Fuzzy Logic Library) [14] that written in $\mathrm{C}++/ \mathrm{C}$ therefore eFLL is a library designed not only for Arduino, but also for any Embedded System written in $\mathrm{C}$.

\subsection{Membership function}

In the fuzzy logic algorithm, this systems uses 3 inputs i.e. temperature, humidity and time. Whereas the output variable is linguistic variable of watering duration i.e. Short (0 - 3000 milliseconds), Medium (2000 - 4000 milliseconds) and Long (3000 - 6000 milliseconds) as shown in Fig. 3. The temperature as input 1 use linguistic variables i.e. Cold $\left(0^{\circ}-27^{\circ} \mathrm{C}\right)$, Cool $\left(24^{\circ}-40^{\circ} \mathrm{C}\right)$, Hot $\left(27^{\circ} \mathrm{C}-30^{\circ} \mathrm{C}\right)$ as shown in Fig. 4. Humidity as input 2 use linguistic variables i.e. Dry $(0 \%-80 \%$ Rh), Moist $(70 \%$ - $90 \% \mathrm{Rh})$ and Wet $(80 \%-100 \% \mathrm{Rh})$ as shown in Fig. 5. Time as input3 use linguistic variables i.e. Morning (010:00), Noon (7:00 - 16:00) and Evening (14:00-23:59) as shown in Fig. 6.

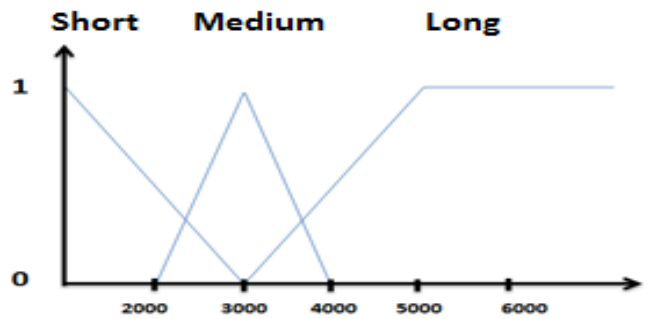

Fig. 3. Membership function of output (spraying duration)

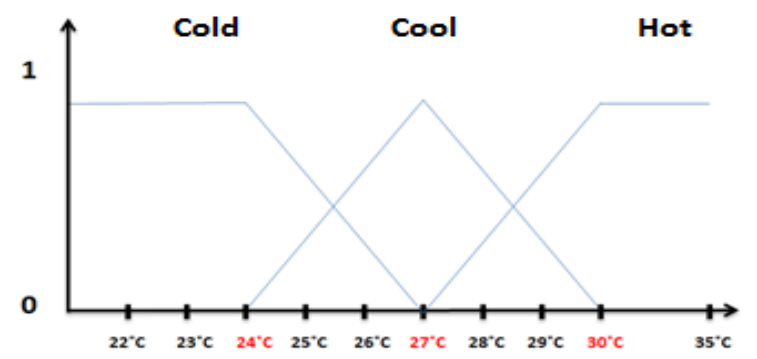

Fig. 4. Membership function of input1 (temperature).

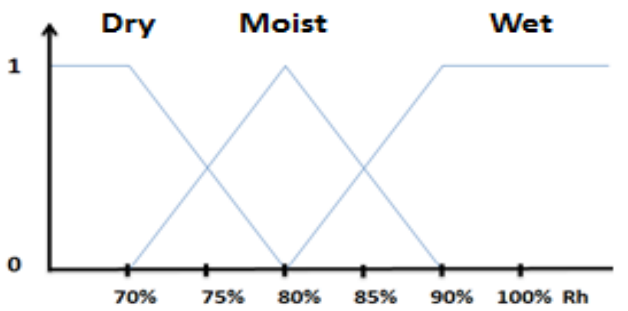

Fig. 5. Membership function of input2 (humidity).

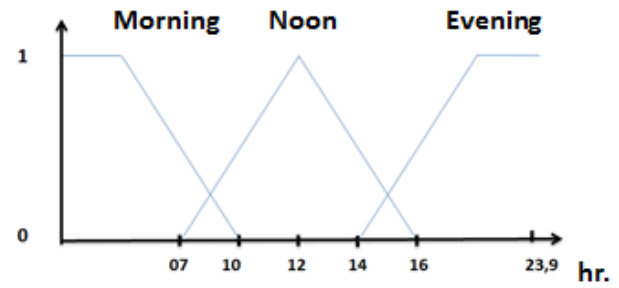

Fig. 6. Membership function of input 3 (time). 


\subsection{Determining fuzzy rule}

There are nine rules in fuzzying process as follows:

- IF Temperature $=$ Cold AND Humidity $=$ Wet JOINWITHOR Time $=$ Morning THEN Duration $=$ Short ;

- IF Temperature $=$ Cool AND Humidity $=$ Wet JOINWITHOR Time $=$ Noon THEN Duration $=$ Short ;

- IF Temperature $=$ Hot AND Humidity $=$ Wet JOINWITHOR Time $=$ Evening THEN Duration $=$ Long ;

- $\quad$ IF Temperature $=$ Cold AND Humidity $=$ Moist JOINWITHOR Time $=$ Morning THEN Duration $=$ Short ;

- $\quad$ IF Temperature $=$ Cool AND Humidity $=$ Moist JOINWITHOR Time $=$ Noon THEN Duration $=$ Medium ;

- IF Temperature $=$ Hot AND Humidity $=$ Moist JOINWITHOR Time $=$ Evening THEN Duration $=$ Long ;

- IF Temperature $=$ Cold AND Humidity $=$ Dry JOINWITHOR Time $=$ Morning THEN Duration $=$ Short ;

- $\quad$ IF Temperature $=$ Cool AND Humidity $=$ Dry JOINWITHOR Time $=$ Noon THEN Duration $=$ Medium ;

- IF Temperature $=$ Hot AND Humidity $=$ Dry JOINWITHOR Time $=$ Evening THEN Duration $=$ Long.

In above rule, sensor3 as Time input is combined in OR conditional with sensor1 as Temperature and sensor2 as Humidity, because Time is important factor as farmer schedule in spraying water to oyster mushroom.

\section{Discussion and results}

The results can be divided two scheme i.e. the embedded system integrated with fuzzy logic controller and mobile and web application for implementing IoT.

\subsection{Prototyping of systems}

The DHT11 as humidity and temperature sensor and RTC module as clock have been connected with Arduino as shown in Fig. 7. Oyster mushrooms are put in the box to make suitable environment similar to maintain humidity and temperature.

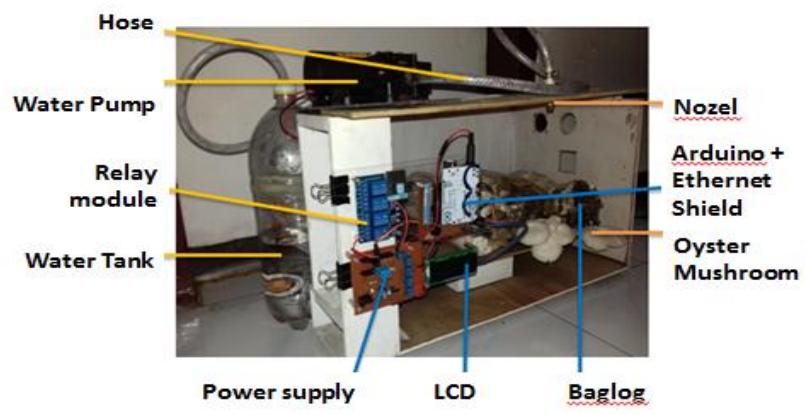

Fig. 7. Overall prototype of embedded system with IoT.
By doing sampling test with the different conditions as shown in Table 1, it can be concluded that the systems can fit the rules and fuzzy logic formula.

Table 1. Fuzzy logic result in embedded systems.

\begin{tabular}{|c|c|c|c|c|}
\hline \multirow{2}{*}{ No. } & \multicolumn{3}{|c|}{ Input } & Output \\
\cline { 2 - 5 } & Temp. & Humidity & Time & $\begin{array}{c}\text { Spraying Time } \\
\text { (ms) }\end{array}$ \\
\hline $\mathbf{1}$ & $23^{\circ} \mathrm{C}$ & $95 \%$ & $06: 00$ & 0 \\
\hline $\mathbf{2}$ & $27^{\circ} \mathrm{C}$ & $90 \%$ & $07: 59$ & 0 \\
\hline $\mathbf{3}$ & $29^{\circ} \mathrm{C}$ & $88 \%$ & $11: 55$ & 3063.49 \\
\hline $\mathbf{4}$ & $32^{\circ} \mathrm{C}$ & $81 \%$ & $14: 00$ & 4711.76 \\
\hline $\mathbf{5}$ & $26^{\circ} \mathrm{C}$ & $90 \%$ & $16: 55$ & 3463.77 \\
\hline
\end{tabular}

\subsection{Information systems for monitoring and controlling}

The Information Systems is installed in Web Server and be able to accessed through internet. This Web Application has several functions such as manual spraying as controlling function, real time monitoring for humidity and temperature, and data logging for all spraying action and sensor values as shown in Fig. 8.

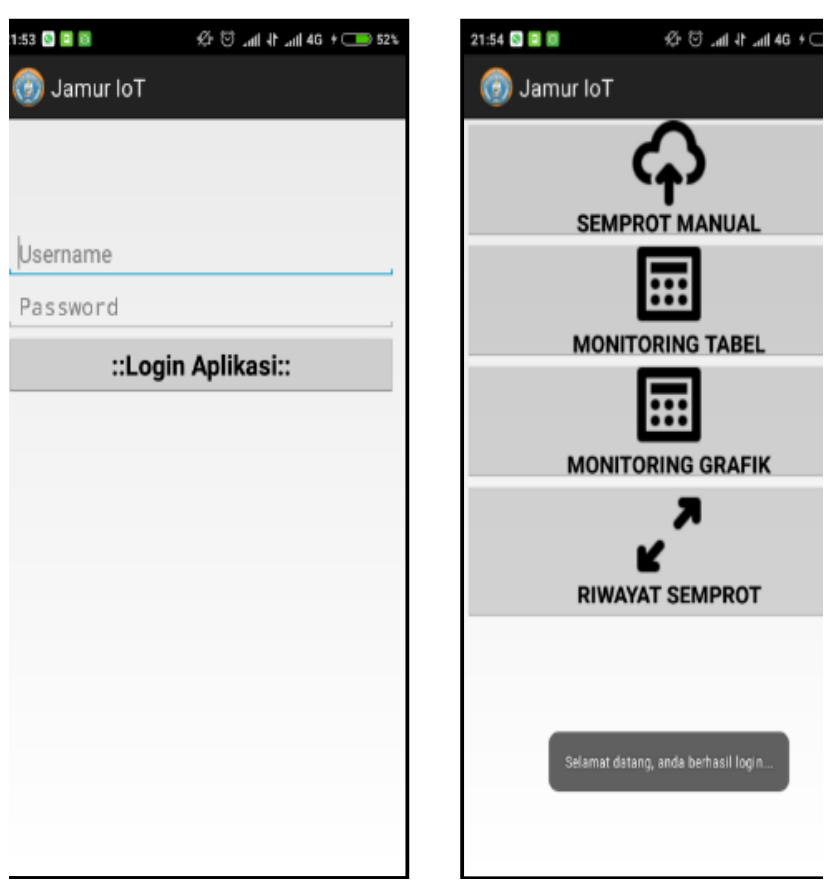

Fig. 8. Login page and function page.

If button of Semprot Manual (Manual Spray) is pushed, it will open other page for controlling water pump to spray as shown in Fig. 9. Other pages are Monitoring Tabel (Table of Monitoring Data), Monitoring Grafik (Monitoring Data Plot) and Tabel Riwayat (Spraying History) are shown in Fig. 10. 


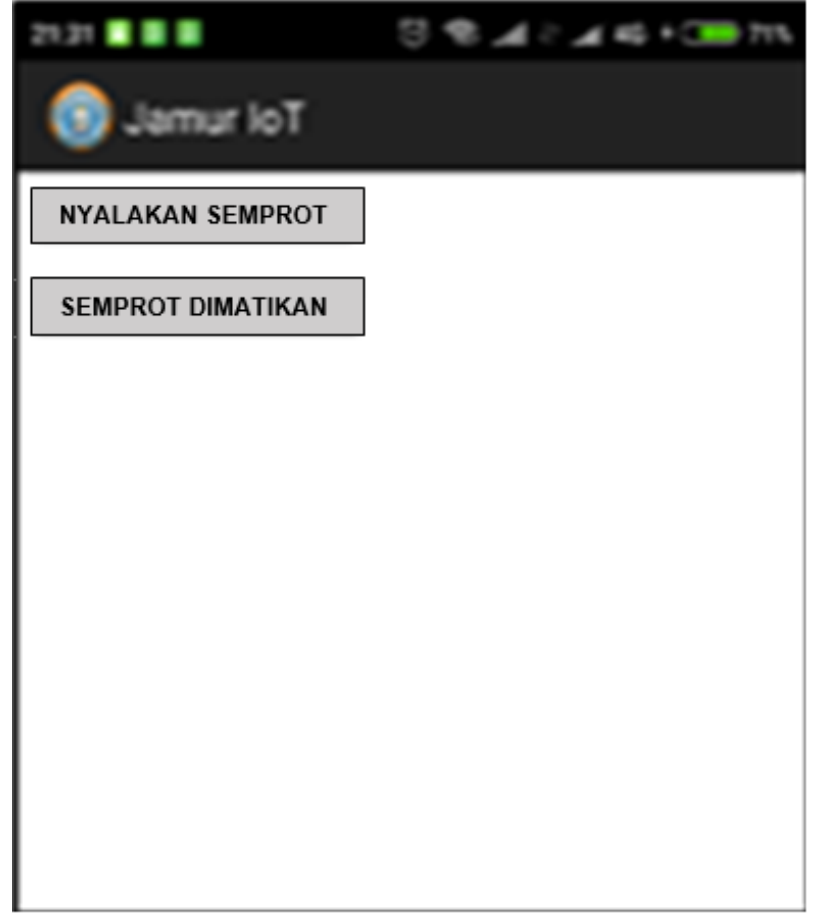

Fig. 9. Semprot manual (manual spraying) page.

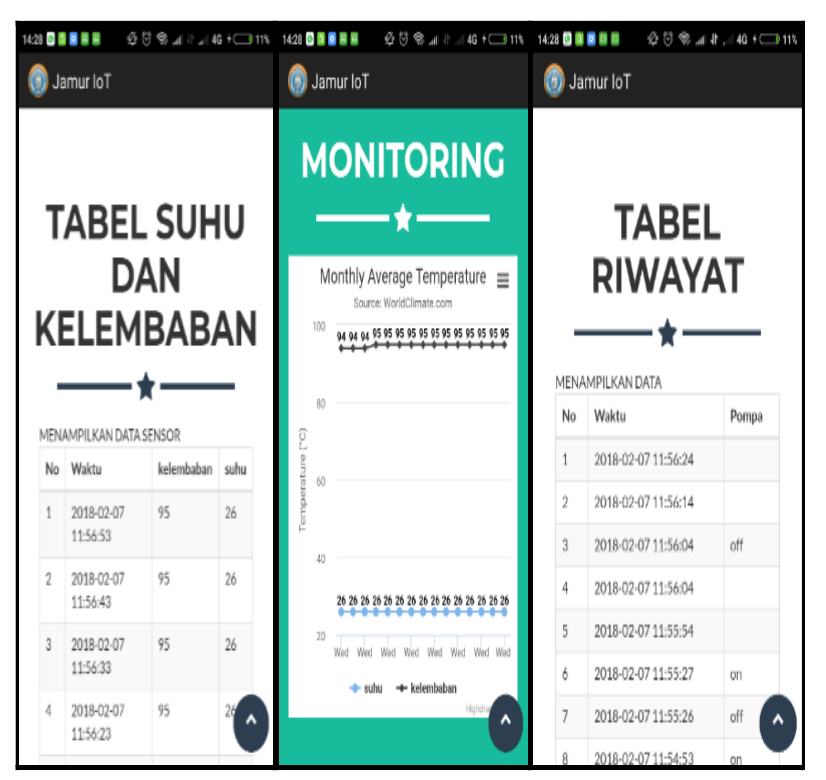

Fig. 10. Pages of monitoring tabel (table of monitoring data), monitoring grafik (monitoring data plot) and tabel riwayat (spraying history).

\section{Conclusion}

The result of monitoring and controlling systems in the form of prototype can be appropriate with previous design. This systems uses fuzzy logic for automatic controlling, whereas the manual controlling is done by web application using Internet of Things technology.

The acknowledgements: this research is funded from Research and Community Service Grant of Universitas Kanjuruhan Malang.

\section{References}

1. E. A. Lee and S. A. Seshia, Introduction to Embedded Systems - A Cyber-Physical Systems Approach, Second Edi. MIT Press, (2017).

2. M. P. T. Sulistyanto, D. A. Nugraha, N. Sari, N. Karima, and W. Asrori, Implementasi IoT (Internet of Things) dalam pembelajaran di Universitas Kanjuruhan Malang, SMARTICS J., 1, 1, pp. 2023, (2015)

3. M. P. T. Sulistyanto, K. Suharsono, and D. A. Nugraha, Monitoring dan Kendali Peralatan Elektronik Menggunakan Logika Fuzzy Melalui Website Dengan Protokol HTTP, J. SMARTICS, 2 , 2, pp. 15-20, (2016)

4. M. P. T. Sulistyanto, K. B. Pranata, and Solikhan, Preliminary study of utilizing Internet of Things for monitoring energy use in building to support energy audit process, in 2017 The 4th International Conference on Computer Applications and Information Processing Technology (CAIPT), pp. 1-7. (2017)

5. Achmad, Panduan Lengkap Jamur. Jakarta: Penebar Swadaya, (2011)

6. D. J. Russell, Introduction to Embedded Systems Using ANSI C and the Arduino Development Environment. .

7. C. LI and W. WANG, Design of Humiture Measurement and Control System Based on DHT11 [J], Mach. Tool Hydraul., 13, p. 35, (2013)

8. M. Banzi and M. Shiloh, Getting started with Arduino: the open source electronics prototyping platform. Maker Media, Inc., (2014)

9. A. G. Smith, Introduction to Arduino. (2011)

10. A. Knörig, R. Wettach, and J. Cohen, Fritzing: a tool for advancing electronic prototyping for designers, in Proceedings of the 3rd International Conference on Tangible and Embedded Interaction, pp. 351-358. (2009)

11. L. A. Zadeh, Fuzzy logic, Computer (Long. Beach. Calif)., 21, 4, pp. 83-93, (1988)

12. R. R. Yager and L. A. Zadeh, An introduction to fuzzy logic applications in intelligent systems, 165. Springer Science \& Business Media, (2012)

13. J. M. Mendel, Fuzzy logic systems for engineering: a tutorial, Proc. IEEE, 83, 3, pp. 345-377, (1995)

14. A. J. Alves, M. Lemos, D. R. Kridi, and K. Leal, eFLL (Embedded Fuzzy Logic Library) v1.0.10. (2011) 